Research Article

\title{
Prescription pattern of drugs in pregnancy induced hypertension in a tertiary care hospital
}

\author{
Naveen Kumar $\mathbf{T}^{1 *}$, Tadvi $\mathbf{N A}^{2}, \operatorname{Kaul} \mathbf{R}^{3}$
}

${ }^{1}$ Department of Pharmacology, Apollo Institute of Medical Sciences and Research, Jubilee Hills, Hyderabad, A.P., India

${ }^{2}$ Department of Pharmacology, ${ }^{3}$ Department of Obstetrics and Gynaecology, Kamineni Institute of Medical Sciences, Narketpally, A.P., India

Received: 5 October 2013

Accepted: 18 October 2013

*Correspondence to:

Dr. Naveen Kumar T,

Email:

doctornaveen1@rediffmail.com

(C) 2013 T Naveen Kumar et al.

This is an open-access article distributed under the terms of the Creative Commons Attribution Non-Commercial License, which permits unrestricted non-commercial use, distribution, and reproduction in any medium, provided the original work is properly cited.

\begin{abstract}
Background: The objective of this study was to evaluate the prescription pattern of drugs in pregnancy induced hypertension in a tertiary care hospital. Methods: A retrospective observational study was conducted by department of Pharmacology in collaboration with the Department of Obstetrics in Kamineni Institute of Medical Sciences, Narketpally after taking permission from the Institutional Review Board. WHO basic indicators were indicators were used for studying the prescribing pattern of drugs.

Results: Out of the total prescriptions studied the most commonly prescribed antihypertensive was Methyldopa, followed by Nifedipine. Amlodipine, Atenolol and Magnesium sulphate were the other drugs prescribed. Majority drugs prescribed were from category B and C. Single drug therapy was prescribed in $46.94 \%$ patients. The use of fixed dose combinations was low.

Conclusion: The incidence of single drugs therapy and two drugs was high. Irrational prescriptions were few. The present pattern of prescriptions can be improved by advocating rational drug prescription and awareness regarding safe use of drugs to the obstetricians.
\end{abstract}

Keywords: Antihypertensives, Drug use indicators, Pregnancy induced hypertension, Drug utilization studies

\section{INTRODUCTION}

Hypertensive disorders are one of the most common disorders in pregnancy. They are amongst the major cause of maternal and perinatal morbidity and mortality. ${ }^{1}$ Hypertension in pregnancy is defined as systolic blood pressure $(\mathrm{sBP}) \geq 140 \mathrm{mmHg}$ and/or diastolic blood pressure $(\mathrm{dBP}) \geq 90 \mathrm{mmHg}$, or by $\uparrow$ in $\mathrm{sBP} \geq 30 \mathrm{mmHg}$, or in $\mathrm{dBP} \geq 15 \mathrm{mmHg}$ from preconception or first trimester blood pressure confirmed by two measuring 6 hours apart. $^{2}$

Several risk factors have been found to be associated with an increased risk of developing preeclampsia: the presence of type 1 diabetes, gestational diabetes, twin birth and obesity (body mass index >29). ${ }^{3}$ The likelihood of progression from gestational hypertension to preeclampsia may be increased by a prior miscarriage. ${ }^{3,4} \mathrm{~A}$ study on a large cohort of Latin American and Caribbean women identified the following risk factors for developing pre-eclampsia: nulliparity, multiple pregnancy, history of chronic hypertension, gestational diabetes, maternal age over 35 years, fetal malformation and obesity. ${ }^{5} \mathrm{~A}$ number of drugs in various combinations are generally used for effective long -term management of hypertension. Therefore ,drug utilization studies, which evaluate, analyze the medical, social and economic outcomes of the drug therapy, are more meaningful and 
observe the prescribing attitude of physicians with the aim to provide drugs rationally. ${ }^{6}$ The World Health Organization (WHO) in 1997 defined drug utilization as the marketing, distribution, prescription, and use of drugs in a society, with special emphasis on the resulting medical, social and economic consequences. ${ }^{7}$ The study of prescribing pattern is a component of medical audit, which seeks monitoring in the prescribing practices of the prescribers to achieve rational and cost effective medical care. ${ }^{8}$ Accordingly there is need to survey the pattern of usage of antihypertensives drugs, to see if the current usage is rational, effective and tolerated and in concordance with current guidelines for treatment of hypertension. ${ }^{9}$

The present study was designed to analyze the physicians prescribing pattern of various antihypertensives, a drug utilization study of both qualitative and quantitative variants, also describing physicians compliance with existing guidelines.

\section{Hypertension in pregnancy is of following major types ${ }^{2}$}

1. Chronic hypertension: Blood pressure (BP) $\geq$ $140 / 90 \mathrm{mmHg}$ is diagnosed before pregnancy in first 20 weeks of gestation or persists 42 days after delivery.

2. Gestational hypertension: Blood pressure $\geq$ $140 / 90 \mathrm{mmHg}$ established after 20 weeks of gestation and not associated with proteinuria.

3. Preeclampsia-eclampsia: Hypertension, proteinuria ( $\geq 0.3 \mathrm{~g} / 24$ hours) and edema after $20^{\text {th }}$ week of gestation. Eclampsia is defined as appearance of generalized convulsions associated with signs of pre-eclampsia, or their occurrence within 7 days of parturition and not caused by epilepsy or other convulsive disorder.

The greatest challenge in treating hypertension in pregnancy is to reduce the blood pressure to assure the safety of mother and at same time not to compromise uteroplacental perfusion or cause harmful effects on the foetus. ${ }^{10}$ The ideal therapy of hypertension in pregnancy should be potent, rapidly acting and without any adverse maternal or foetal effect.

The aim of the present study was to investigate the drug utilization pattern of antihypertensive drugs in pregnancy induced hypertension.

\section{METHODS}

A retrospective observational study was conducted by Department of Pharmacology in collaboration with the Department of Obstetrics in Kamineni Institute of Medical Sciences, Narketpally after taking permission from the Institutional Review Board. The Case record sheets of the patients diagnosed for pregnancy induced hypertension or gestational hypertension admitted to the obstetrics ward for the past 6 months were reviewed. The information regarding total number of drugs prescribed, with dosage, frequency, duration were recorded and from this the core indicators like prescribing indicators and complementary indicators were evaluated.

\section{Prescribing indicators ${ }^{11}$}

a) Average number of drugs per patient was calculated by dividing the total number of different drug products prescribed by the number of patients surveyed.

b) Percentage of drugs prescribed by generic name was determined by dividing the number of drugs prescribed by generic name by the total number of drugs prescribed, multiplied by 100 .

c) Percentage of drugs prescribed from essential drug list was determined by dividing the number of products prescribed from essential drug list of the hospital by the total number of drugs prescribed, multiplied by 100 .

\section{Complementary Indicators}

Effect of the drug on the foetus (Low birth Weight, IUGR, death or defect, were also recorded)

The prescribed drugs also reviewed for their category and safety.

\section{Definition of risk factors ${ }^{12}$}

\section{Category A}

Controlled studies in women fail to demonstrate a risk to the foetus in any trimester and the possibility of foetal harm remains remote.

\section{Category $B$}

Either animal-reproduction studies have not demonstrated a foetal risk but there are no controlled studies in pregnant women or animal-reproduction studies have shown an adverse effect (other than a decrease in fertility) that was not confirmed in controlled studies in women in the $1^{\text {st }}$ trimester(and there is no evidence of a risk in later trimesters).

\section{Category $C$}

Either studies in animals have revealed adverse effects on the foetus (teratogenic or embryocidal or other) and there are no controlled studies in women and animals are not available. Drugs should be given only if the potential benefits justify the potential risk to the foetus.

\section{Category $D$}

There is positive evidence of human foetal risk, but the benefits from use in pregnant women may be acceptable 
despite the risk (e.g. if the drug is needed in a lifethreatening situation or for a serious disease for which safer drugs cannot be used or are ineffective)

\section{Category $X$}

Studies in animals or human beings have demonstrated foetal abnormalities or there is evidence of foetal risk based on human experience or both, and the risk of the use drug in pregnant women clearly outweighs any possible benefits. The drug is contraindicated in women who are, or may become pregnant.

\section{RESULTS}

Among prescriptions collected $12 \%$ were with eclampsia, $4 \%$ were with placental abruption, $2 \%$ were with oligohydramnios and polyhydramnios and $4 \%$ with anemia.

Table 1: Demographic distribution of the patients.

\begin{tabular}{|lll|}
\hline Age groups & $\begin{array}{l}\text { Number of } \\
\text { patients }\end{array}$ & Percentage \\
\hline $18-20$ & 13 & 26.51 \\
\hline $21-25$ & 26 & 53.07 \\
\hline $26-30$ & 02 & 4.09 \\
\hline $31-35$ & 08 & 16.33 \\
\hline
\end{tabular}

Table 2: Gravidity wise distribution of patients.

\begin{tabular}{|lll|}
\hline Gravida & $\begin{array}{l}\text { Number of } \\
\text { patients }\end{array}$ & Percentage \\
\hline Primi & 28 & 57.14 \\
\hline Second & 14 & 28.57 \\
\hline Third & 05 & 10.21 \\
\hline Fourth & 02 & 4.08 \\
\hline
\end{tabular}

Table 3: Blood pressure range of patients before administration of drugs.

\begin{tabular}{|llll|} 
BP range & $\begin{array}{l}\text { BP }(\mathrm{mmHg}) \\
\text { s/d** }\end{array}$ & $\begin{array}{l}\text { Number } \\
\text { of patients }\end{array}$ & Percentage \\
\hline Mild & $\begin{array}{l}140-159 / 90- \\
99\end{array}$ & 16 & 32.65 \\
\hline Moderate & $\begin{array}{l}160-179 / \\
100-109\end{array}$ & 17 & 34.70 \\
\hline Severe & $>180 / 110$ & 16 & 32.65 \\
\hline
\end{tabular}

*s/d: systolic/ diastolic blood pressure
Table 4: Maternal complications.

\begin{tabular}{|lll|}
\hline $\begin{array}{l}\text { Maternal } \\
\text { complications }\end{array}$ & $\begin{array}{l}\text { Number of } \\
\text { patients }\end{array}$ & Percentage \\
\hline Eclampsia & 06 & 12.24 \\
\hline Placental abruption & 02 & 4.08 \\
\hline Oligohydramnios & 01 & 2.04 \\
\hline Polyhydramnios & 01 & 2.04 \\
\hline Anemia & 02 & 4.08 \\
\hline
\end{tabular}

Table 5: Neonatal outcomes.

\begin{tabular}{|lll|}
\hline $\begin{array}{l}\text { Neonatal } \\
\text { outcome }\end{array}$ & $\begin{array}{l}\text { Number of } \\
\text { patients }\end{array}$ & Percentage \\
\hline $\begin{array}{l}\text { Low birth } \\
\text { weight }\end{array}$ & 11 & 22.45 \\
\hline Foetal distress & 02 & 4.08 \\
\hline IUGR & 02 & 4.08 \\
\hline Death & 01 & 2.04 \\
\hline
\end{tabular}

Table 6: Prescribing pattern of drugs in hospital.

\begin{tabular}{|lll|}
\hline Drug therapy & $\begin{array}{l}\text { Number of } \\
\text { patients }\end{array}$ & Percentage \\
\hline Single drugs & 23 & 46.94 \\
\hline Two drugs & 18 & 36.74 \\
\hline Three drugs & 7 & 14.87 \\
\hline More than 3 drugs & 1 & 2.05 \\
\hline Fixed dose combination & 6 & 12.24 \\
\hline
\end{tabular}

Table 7: Name of antihypertensives used and their frequency.

\begin{tabular}{|lll|}
\hline Name of drug used & Frequency & $\begin{array}{l}\text { Category of } \\
\text { drug }\end{array}$ \\
\hline Methyl dopa & 34 & B \\
\hline Nifedipine & 32 & C \\
\hline Amlodipine & 7 & C \\
\hline Atenolol & 6 & D \\
\hline Magnesium sulfate & 6 & A \\
\hline Telmisartan & 1 & D \\
\hline Hydrochlorothiazide & 1 & B \\
\hline
\end{tabular}


Table 8: Details of drug use indicators.

\begin{tabular}{|ll|}
\hline Indicators & Data \\
\hline Core indicators & \\
\hline $\begin{array}{l}\text { Average drugs prescribed per } \\
\text { prescription }\end{array}$ & 4.4 \\
\hline $\begin{array}{l}\text { Average number of } \\
\text { antihypertensives per } \\
\text { prescription }\end{array}$ & 1.76 \\
\hline Prescriptions by generic name & $13 \%$ \\
\hline On essential list & $82 \%$ \\
\hline Facility indicators & Yes \\
\hline Availability of EDL & Yes (100\%) \\
\hline Key drugs available &
\end{tabular}

\section{DISCUSSION}

Rational drug use in pregnancy requires balancing of benefits and the potential risks associated with the use of drugs. ${ }^{13}$ One of the most common ailments in pregnancy which requires drug therapy is Pregnancy Induced Hypertension (PIH). The most commonly prescribed antihypertensives were methyldopa and nifedipine. Methyldopa is the safest antihypertensive in pregnancy followed by Nifedipine. Calcium channel blockers should not be given as first line drugs because they can inhibit the contractions of uterus. Single drug therapy was prescribed in $46.94 \%$ patients only so we can comment that multidrug therapy is more commonly used PIH.

The majority of drugs used in this study were from Category B and C but the use of category D drug like atenolol and telmisartan was observed in 6 and 1 patient respectively. Though they were rarely used in third trimester and did not affect the outcome of the foetus they should not be used in pregnancy as more safe drugs are available. The incidence of PIH was highest among primigravida $(57.14 \%)$ in our study this co-relates with study by Tanuja et al (2010). ${ }^{14}$ The most common maternal complication seen was eclampsia seen in $12.24 \%$ of patients. The most common neonatal outcome was low birth weight baby. The co-relation of the effect of PIH on foetal weight should be evaluated further by planning more studies. The incidence of IUGR, premature babies and foetal distress were also noticed albeit it cannot be co-related to PIH or drugs used in this study.

The use of fixed drug combinations was low this may be because of difficulty in titrating the dose with fixed dose.

\section{CONCLUSION}

Hypertension in pregnancy is one of the most common disorders encountered in pregnancy. Though many drugs are available it is still safe to use methyldopa followed by calcium channel blockers. The use of multidrug therapy should be more rationale. The incidence of Low birth weight babies was high which may be due to either effect of maternal hypertension or drugs which should be evaluated by further studies. The limitation of the present study is its low sample size, and the data is insufficient to favour any particular antihypertensive. The cost benefit analysis was not performed as this is a retrospective study. More such studies should be done to evaluate the prescription pattern and education and awareness regarding the safe use of drugs should be provided to the obstetricians.

\section{Funding: None}

Conflict of interest: None declared

Ethical approval: The study was approved by the Institutional Review Board

\section{REFERENCES}

1. Roberts J, Pearson G, Cutler J, Lindheimer M. Summary of the NHLBI working group on research on hypertension during pregnancy. Hypertens 2003;41(3):437-45.

2. Folic M, Folic N, Varjacic M, Jakovljevic M, Jankovic S. Antihypertensive drug therapy for hypertensive disorders in pregnancy. Acta Medica Medianae.2008;47(3):67-71.

3. Saudan P, Brown MA, Buddle ML et al. Does gestational hypertension become pre-eclampsia. British Journal of Obstetrics and Gynaecology,1998,105(11):1177-84

4. Lankoande J, Ouedraogo A, Ouedraogo CM. Gynecology-obstetrics at the Yalgado- Ouedraogo National Hospital Center. Eclampsia: epidemiologic, clinical and prognostic aspects Sante, 1997;7(4):231-5.

5. Conde Agudelo A, Beliza JM. Risk factors for preeclampsia in a large cohort of Latin American and Caribbean women. BJOG 2000;107(1):75-83.

6. Tiwari H, Kumar A, Kulkarni SK. Prescription monitoring of antihypertensive drug utilization at the Punjab university health centre in India. Singapore Med J 2004;45(3):117.

7. WHO Expert Committee. The selection of Essential Drugs, Technical Report Series no.615. Geneva:World Health Organization, 1977.

8. Gupta N, Sharma D, Garg SK, Bhargava VK. Auditing of prescriptions to study utilization of antimicrobials in tertiary hospital. Indian $\mathbf{J}$ Pharmacol,1997;29(6):411-5

9. Pai PG, Shenoy J, Sanji N. Prescribing Patterns of antihypertensives drugs in a south Indian tertiary care hospital. Drug Invention Today 2011;3(4):3840 . 
10. Venkateshwaramurthy N, John Christy, Perumal P. Study on antihypertensives in pre-eclampsia. Asian Journal of Pharmaceutical and Clinical Research 201;5(3):126-8.

11. Sachdeva PD, Patel BG. Drug utilization studiesScope and future perspectives. International Journal on Pharmaceutical and Biological Research 2010;1(1):11-6.

12. Drug facts \& Comparison 2005, FDA Pregnancy categories A-4.
13. Sharma R, Kapoor B, Verma U. drug utilization pattern during pregnancy in North India. Indian $\mathrm{J}$ Med Sci. 2006;60(7):277-86.

14. Tanuja VH, Santosh Kumar J, Manjunath S, Vinod Kumar CS. Drug utilization study of antihypertensives in obstetric practice in a tertiary care hospital. IJACPT. 2010;1(3):1006-10.

doi:10.5455/2319-2003.ijbcp20131221

Cite this article as: T Naveen Kumar, Tadvi NA, Kaul R. Prescription pattern of drugs in pregnancy induced hypertension in a tertiary care hospital. Int J

Basic Clin Pharmacol 2013;2:783-7. 